\title{
AGUSTÍN ESPINOSA, ESPECTADOR DEL ESPACIO INSULAR: LA INFLUENCIA DEL CINE EN LANCELOT, 28ำ-7(1929)
}

\author{
Alberto García-Aguilar \\ Universidad de La Laguna
}

\section{Resumen}

La descripción vanguardista de la isla de Lanzarote que Agustín Espinosa desarrolla en Lancelot, $28^{\circ}-7^{\circ}(1929)$ demuestra que el escritor compartió el mismo interés por el cine que otros jóvenes escritores expresaron en sus obras durante los años veinte. Sin embargo, esta relación interartística entre literatura y cine en Lancelot no se ha examinado aún con detenimiento. Por ello, este artículo intentará estudiar las diferentes maneras en las que el cine ha influido en Lancelot, que incluyen no solo referencias a estrellas del cine mudo estadounidense, sino también el uso de técnicas cinematográficas. De esta manera, Espinosa ofrece nuevas imágenes de la isla, ahora fusionada con movimientos artísticos universales. Para analizar este particular uso del bagaje fílmico de Espinosa en Lancelot, el artículo estudiará el interés por el cine que el escritor mostró a lo largo de su vida, el modo en el que usa distintas técnicas fílmicas en esta obra, las imágenes poéticas vinculadas con el cine y las referencias a estrellas del cine incluidas en el texto.

PALABRas Clave: literatura y cine, vanguardias, Islas Canarias, Agustín Espinosa, cine mudo.

$$
\begin{aligned}
& \text { AGUSTÍN ESPINOSA, SPECTATOR OF THE INSULAR SPACE: } \\
& \text { THE INFLUENCE OF CINEMA IN LANCELOT, } 28^{\circ} 7^{\circ}(1929)
\end{aligned}
$$

\section{Abstract}

The avant-garde description of the island of Lanzarote that Agustín Espinosa developed in Lancelot, $28^{\circ}-7^{\circ}(1929)$ proves that the writer shared the same interest in cinema that other young writers had expressed in their works during the 20 s. However, the interartistic relation between cinema and literature in Lancelot has not been examined carefully yet. For this reason, this paper tries to study the different ways the cinema has influenced Lancelot, which includes not only references to film stars from the Amercian silent cinema, but also using certain film techniques. Thus, Espinosa offers new images of the island, now merged with universal artistic movements. To analyze this particular use of Espinosa's cinema background in Lancelot, this paper will study the interest in cinema that the writer showed along his life, the way he uses different film techniques, the poetic imagery related to cinema, and the references to film stars included in the text.

KeYwords: literature and cinema, avant-gardes, Canary Islands, Agustín Espinosa, silent cinema. 


\section{INTRODUCCIÓN}

Al igual que sucedió con muchos jóvenes escritores de los años veinte, la pasión que Agustín Espinosa sintió por la gran pantalla se expresó en los distintos recursos cinematográficos que usó en sus escritos. Esta combinación de lenguajes artísticos se aprecia con claridad en su libro Lancelot, $28^{\circ}-7^{\circ}(1929)$, donde el autor realiza una corografía vanguardista de la isla canaria de Lanzarote y describe su paisaje, su historia y su mitología, que Espinosa inventa para la ocasión. Así, el texto se inserta dentro de los objetivos planteados por el grupo literario que se formó en torno a la revista La Rosa de los Vientos (Tenerife, 1927-1928), al que pertenecía el escritor. Estos autores pretendían unir la tradición insular con las últimas corrientes artísticas europeas y, de esa manera, desarrollar un "proyecto universalista» (Palenzuela 2002 [1988]: 12) libre de regionalismos.

No obstante, la escasa atención que la crítica literaria ha dedicado a la presencia del cine en Lancelot justifica un análisis detenido de este aspecto del texto. Aunque De la Nuez Caballero (1983) y Heredia (1992) no hablan de esta influencia cinematográfica, la mayoría de investigadores que se han acercado a la obra la mencionan. Armas Ayala opina que el «azorinismo de la prosa» se apoya «en ese travelling cinematográfico que el escritor ha sabido construir ingeniosamente» (1992: 272) al describir la isla. Aunque no especifica dónde aprecia esa técnica fílmica, en trabajos anteriores había advertido la existencia de un travelling en el capítulo que Espinosa dedica al pueblo de Nazaret (Armas Ayala 1960: 28; Armas 1974: 24). De un modo ambiguo, también habla sobre la «sensación de documental cinematográfico» (Armas 1968: VII) que transmite la lectura del texto. Martín Rodríguez afirma que Lancelot posee «una estructura muy cinematográfica y constantes alusiones al mundo del cine» (1992: 166). Trujillo (2019 [1929]: 301), Llarena (2000: 67), Palenzuela (2002 [1988]: 22), Castells (2009: 28), Díaz Arenas (2015: 42) y Betancort Mesa (2019: 30) señalan la mención en Lancelot de Charlie Chaplin y de su personaje Charlot, mientras que Gómez Gutiérrez (2008: 479-482) recuerda la importancia de este actor para Espinosa. Sin embargo, en estos trabajos no se profundiza en la motivación del empleo de las técnicas cinematográficas ni se especifica qué recursos fílmicos se han utilizado. Tampoco existen referencias al cine en el prólogo de Carlos Müller (2006) a la traducción de Lancelot al alemán, ni en las dos ediciones de varias obras del escritor (Espinosa, 2014; 2018) publicadas en la editorial La Página.

Pérez Corrales, el mayor investigador sobre la vida y la obra de Espinosa, sí trata la influencia del cine en Lancelot con cierta extensión. Aunque no alude a ella en el apéndice de su edición de la obra (Pérez Corrales 2019 [2013]: 305-352), le dedica un apartado en otros dos extensos estudios sobre Lancelot (Pérez Corrales 1983: 467-470; 1986a: 402-404). Pérez Corrales, además de explicar con exhaustividad el interés de Espinosa por el cine (1986a: 107-123), enumera a los actores que se nombran en el texto y aprecia la influencia fílmica en algunos pasajes (Pérez Corrales 1986a: 403-404). Sin embargo, no precisa qué técnicas cinematográficas se han usado.

Así, partiendo de las aportaciones de los investigadores citados, este artículo pretende determinar cómo ha influido el cine en Lancelot. Primero, se estable- 
cerá la relación de Espinosa con el cine. Segundo, se explicarán los objetivos que el autor persigue con este libro y se vinculará la obra con el concepto de corografía, que Espinosa reinventa desde una postura vanguardista. Tercero, se analizarán los distintos recursos cinematográficos presentes en el texto, usando la primera edición de la obra como objeto de estudio. Para ello, se examinarán los movimientos y los planos fílmicos, las imágenes poéticas de carácter cinematográfico y las referencias intertextuales al mundo del cine.

\section{EL ESPECTADOR ENTUSIASTA: AGUSTÍN ESPINOSA Y EL CINE}

De la relación de los escritores españoles de vanguardia con el cine surgieron obras que reflejaron el enorme interés que sentían por este medio durante los años veinte. Cinelandia (1923), de Ramón Gómez de la Serna, supuso una de las primeras narraciones significativas que combinaron la literatura con el cine. Esta obra recrea una ciudad inspirada en Hollywood donde la industria cinematográfica lo domina todo. Gómez de la Serna ofrece una visión humorística de la vida de sus habitantes, involucrados en rodajes constantes, aunque sin olvidar algunos de sus aspectos más turbios. La violación que sufre la joven actriz Carlota Bray (Gómez de la Serna 1923: 251) representa el episodio más oscuro de la obra. También Pío Baroja manifestó su interés por el cine con El poeta y la princesa o El cabaret de la Cotorra Verde (1929), que subtituló «Novela-film». El autor concibió este texto como un guion cinematográfico que contiene indicaciones técnicas para su rodaje. Del mismo modo, Federico García Lorca expresó su cinefilia en textos como el poema en prosa "La muerte de la madre de Charlot» (2002 [1928]: 66-70) y en la breve pieza teatral El paseo de Buster Keaton (2008 [1928]), inspirados en dos de los personajes más relevantes del cine cómico mudo. Rafael Alberti, movido por esta misma pasión, incluyó en Yo era un tonto y lo que he visto me ha hecho dos tontos (1981 [1929]: 170-172) el poema «Buster Keaton busca por el bosque a su novia, que es una verdadera vaca», que también se inspira en el actor estadounidense.

En Canarias, Emeterio Gutiérrez Albelo, en Romanticismo y cuenta nueva (1933), publicó poemas con referencias a Charlot (1933: 63-64), a Greta Garbo (1933: 57), a Brigitte Helm (1933: 58-59) y a Joan Crawford (1933: 61). En estos textos no solo se hallan referencias a estrellas de la gran pantalla, sino también técnicas cinematográficas trasladadas a la literatura. En «minuto a brigitte helm» el autor evoca, mediante la anáfora del verbo «avanzando» en varios versos (Gutiérrez Albelo 1933: 58), un travelling de la película alemana Mandrágora (Alraune, 1928), de Henrik Galeen, en el que el rostro de la actriz se dirige hacia la cámara ${ }^{1}$.

${ }^{1}$ En 1931 el periódico La Prensa, publicado en Santa Cruz de Tenerife, anunció la proyección de Mandrágora en el Royal Cinema de Icod de los Vinos («Desde Icod. De cine», 1931 [10 de mayo]: 2), el pueblo donde vivía Gutiérrez Albelo. 
También el poema "Escándalo»², de Domingo López Torres, contiene una referencia a la actriz Anny Ondra y a la pasión amorosa de una pareja de espectadores que disfrutan de una película (García de Mesa 2008: 640). En narrativa, el tinerfeño José M. Benítez Toledo, en el epílogo de su novela Charlestón (1928), explica que ha trasladado técnicas fílmicas a la literatura: «Una derivación cinematográfica de escenas novelescas. Una expresión del movimiento y de la emoción cinematográficos, vertidos en palabras» (Benítez Toledo 1928: 62).

Sin embargo, Agustín Espinosa fue el autor canario de vanguardia que más recurrió al cine en sus escritos. Sus frecuentes visitas a Madrid, adonde "volvió repetidas veces» (Pérez Corrales 1986: 12), desempeñaron un papel importante en su pasión por este medio. En la capital no solo disponía de un mayor número de salas cinematográficas, sino que también entró en contacto con los miembros de La Gaceta Literaria (Madrid, 1927-1931). Esta revista confió su sección de cine a Luis Buñuel e incluso fundó el primer cineclub de la península ibérica en 1928 (Gubern 1999: 84). Como recuerda Castilla, en este cineclub, que funcionó hasta 1931, se proyectó «lo más destacado de la cinematografía mundial» (1985: 20). Espinosa mantuvo una estrecha relación con la revista, pues publicó en ella varios artículos. Además, realizó un cameo en el corto Noticiario del Cineclub (1930), de Ernesto Giménez Caballero, fundador y director de La Gaceta Literaria. En esta película participaron numerosas figuras intelectuales de esa época, como Pío Baroja, Ramón Ménendez Pidal, Pedro Salinas, Salvador Dalí y Edgar Neville, entre otros. La aparición de Espinosa se limita a unos segundos, en los que se le ve junto a colaboradores de $\mathrm{La}$ Gaceta literaria en una azotea ${ }^{3}$. A pesar de la brevedad del cameo, demuestra que el autor se interesaba por las novedades cinematográficas que se rodaban en España.

Esta curiosidad por el cine se refleja también en diferentes textos que el escritor publicó a lo largo de su vida. Con la lectura de varios de sus artículos se comprueba que Espinosa consideraba el cine como parte fundamental del siglo xx, tal como afirma en «Elogio de la burbuja» (1931): «En el siglo del cinema y del jazz, del avión y del "pullover", del rascacielo [sic] y del deporte, del cubismo y de la radiofonía» (Espinosa 2017 [1931]: 112). El autor incluye este medio audiovisual junto con el resto de actividades, de corrientes artísticas y de inventos que conformaban el imaginario de las vanguardias en los años veinte. Del mismo modo, en su artículo «Un coleccionista en el cine» (1933), Espinosa evoca los cielos de las películas La máscara de hierro (The Iron Mask, 1929), de Allan Dwan; La cuadrilla deshecha (The Lost Squadron, 1932), de George Archainbaud; y El chico (The Kid, 1921), de Charles Chaplin (Pérez Corrales 2018: 201). La estética que el escritor encuentra en estos cielos le inspira una exaltación de las posibilidades creativas de este medio: «El arte del porvenir tiene ya otro nombre: se llama "Cinema"» (Espinosa 2018 [1933]b: 200).

\footnotetext{
2 Aunque este texto quedó inédito al morir el autor y no está fechado, García de Mesa (2008: 632) cree que López Torres lo escribió entre 1933 y 1936.

3 Pérez Corrales (1986b: 771) recoge uno de los fotogramas de esta escena.
} 
En su labor pedagógica, Espinosa fomentó el amor hacia el cine entre sus alumnos. En una revista titulada Hoja Azul, que el escritor preparaba con sus estudiantes del Instituto Pérez Galdós de Las Palmas de Gran Canaria, Espinosa incluía el cine entre los principales intereses del siglo xx (Martín Rodríguez 1992: 166). Asimismo, convocó un concurso, llamado «El cine como instrumento de cultura», para que los jóvenes conocieran mejor este medio (Martín Rodríguez 1992: 166). El cine, por tanto, abarcó todas las facetas en las que Espinosa incursionó.

\section{LANCELOT, $28^{\circ}-7^{\circ}$, UNA COROGRAFÍA VANGUARDISTA DE LANZAROTE}

Espinosa definió Lancelot como una "guía integral» (Espinosa 1929: 8) de Lanzarote. Pérez Corrales (1986a: 411) explica que, para Espinosa, el adjetivo «integral» significa "poético». Por eso, esta nueva guía rompe con las descripciones costumbristas que hasta el momento existían de la isla, que la habían «explicado de manera anecdótica, inafectiva. [...] como Tierras sedientas de Francisco González, o Costumbres canarias de Isaac Viera» (Espinosa 1929: 11). Su objetivo consiste en crear una isla nueva desde una perspectiva vanguardista: «Mi intento es el de crear un Lanzarote nuevo. Un Lanzarote inventado por mí. Siguiendo la tradición más ancha de la literatura universal» (Espinosa 1929: 12). A pesar de que en esta cita Espinosa solo menciona la tradición literaria, también sigue la del arte universal y, por supuesto, la del cine.

Según Pérez Corrales, Espinosa parodia en Lancelot las guías turísticas al introducir datos geográficos pero humorísticos: "Así habla de "alzada" (estatura de los animales) de la isla, debido a su anterior calificación de "isla potra", procedente a su vez de la comparación con un caballo; da un "nombre de la infancia" a Lanzarote» (Pérez Corrales 1983: 501-502). Al analizar estos rasgos, Pérez Corrales concluye que «Espinosa inaugura un género nuevo» (1986a: 445). No obstante, Espinosa en realidad reinventa un género ya existente: el de la corografía, que González Maya define como «la suma de la descripción topográfica o geográfica y la histórica [de un territorio]» (2017: 412).

Los textos corográficos describen regiones con más o menos exhaustividad, dependiendo de los objetivos que se haya marcado su autor. Cuentan con una amplia tradición que se remonta, como mínimo, al siglo i d.C. con la Corografía de Pomponio Mela, que contenía «una descripción del orbe conocido, salpicado de abundantes datos históricos, mitológicos, etnográficos, etc.» (Guzmán Arias 1989: 21). Vilá Valentí, en su recorrido histórico por las distintas modalidades corográficas practicadas en España, señala que las corografías renacentistas incluían «citas y datos referentes a localizaciones, superficies, población y actividades económicas, las agrarias en especial» (1989: 35). Asimismo, durante la Ilustración las corografías les darán mayor importancia a «los aspectos humanos» (Vilá Valentí 1989: 52), mostrando así información sobre la cultura o el arte de los territorios.

La particularidad de Lancelot radica en que la obra retoma este antiguo modelo de estudio geográfico y rompe con sus convenciones para crear una coro- 
grafía vanguardista de Lanzarote. Espinosa recurre no solo a datos geográficos, sino también históricos y culturales. Por tanto, realiza una descripción «integral» de Lanzarote, pues comprende todos sus aspectos. De esta manera, al detallar la orografía de la isla se habla de personas ilustres, como Clavijo y Fajardo, y de distintos movimientos y lenguajes artísticos. La isla se ve a través de una mirada que encuentra imágenes inéditas en cualquier lugar, y así el autor actualiza su paisaje, su tradición y su historia.

En esta nueva corografía el cine ejerce una influencia decisiva. Espinosa, con un peculiar uso de las técnicas y de las referencias cinematográficas, transforma la relación que hasta entonces había mantenido el paisaje canario con el medio audiovisual. En la literatura canaria de los años veinte, sobre todo en la segunda mitad de la década, se publicaron obras que proponían llevar a la pantalla parajes insulares para promocionarlos entre los turistas. Flor de los campos (1929), de Alfredo Fuentes $^{4}$, se subtituló «novela cinematográfica» porque, tal como el autor explica en el prólogo, se escribió para su rodaje (Fuentes 1929: 6). La trama se desarrolla, en gran parte, en el pueblo tinerfeño de La Orotava para mostrar paisajes llamativos de la isla y atraer a posibles visitantes: «Se ha atendido, como se observará, más que al fundamento de la materia, a procurar que en la pantalla aparezca lo más notable, bello y atrayente de todas las regiones de la isla» (Fuentes 1929: 6). Sin embargo, la narración posee un marcado carácter costumbrista, ya que el autor se ha interesado, sobre todo, por reflejar el folclore de Tenerife.

En La herencia de Augusto Darley (1927-1928), de Eduardo Díez del Corral, publicada por entregas en la revista tinerfeña Hespérides (Santa Cruz de Tenerife, 1926-1929), existe la misma relación entre paisaje y cine. El autor también la subtituló como "novela cinematográfica», aunque en realidad es un guion de cine con indicaciones técnicas y división de escenas. En la primera entrega Díez del Corral explicitó su objetivo: «El propósito de esta película es el de divulgar ante el mundo cinematográfico tipos, costumbres, industrias, paisajes..., algo, en fin, de lo mucho que encierra la bella isla de Tenerife» (Díez del Corral 1927 [11 de diciembre]: 14). Al igual que en Flor de los campos, una trama costumbrista sirve como excusa para incluir bailes tradicionales, referencias a las temperaturas primaverales, la hospitalidad de los habitantes y, en definitiva, una visión idílica de la isla. Además, Díez del Corral inserta fotografías de distintos lugares de Tenerife (como el bosque de Las Mercedes, una cueva junto al mar o el Teide) para sugerir al futuro director escenarios naturales para el rodaje. Así, al mostrar la variedad paisajística de la isla y su folclore, se promociona Tenerife como destino turístico.

El vínculo entre el cine y el turismo en Canarias se reflejó también en la película La hija del «Mestre» (1928), que dirigió Francisco González González. La melodramática historia de amor que cuenta transcurre en el barrio marinero de San Cristóbal, en Las Palmas de Gran Canaria. Sin embargo, los primeros minutos no guardan relación con el argumento. El largometraje ofrece al principio una visión

\footnotetext{
${ }^{4}$ Pseudónimo del escritor tinerfeño Francisco Dorta (Dandin 1926: 14).
} 
idealizada de Gran Canaria, en la que fotogramas que muestran paisajes hermosos se combinan con rótulos que exaltan la naturaleza de la isla y la modernidad de su capital: «El progreso va dejando sentir su acción poderosa» (González González, 1928). El objetivo, una vez más, consiste en que los turistas visiten Gran Canaria gracias a sus idílicas presentaciones en la gran pantalla.

Lancelot supone una transgresión respecto a estas representaciones del paisaje, la cultura y la historia canarias. El turismo sigue presente en el texto, pero para parodiarlo, como refleja el tratamiento que se da al sepulcro del caballero Lancelot, que, en la ficción de Espinosa, vivió en la isla desde tiempos remotos. Este espacio, que pertenece a la nueva mitología que el autor crea para Lanzarote, se incluirá en futuras guías para atraer a más público: "Cuando la Sociedad Pro Turismo de Lanzarote se dé cuenta de este imperativo turístico, edificará el sarcófago de Lancelot que señalarán con mayúscula las nuevas guías» (Espinosa 1929: 23). Con ello, Espinosa huye de los tópicos y del costumbrismo. Su objetivo no consiste en atraer visitantes a Lanzarote, sino en crear una isla nueva en la que se refleje una visión universalista de la insularidad canaria.

\section{LOS RECURSOS CINEMATOGRÁFICOS EN LANCELOT, $28^{\circ}-7^{\circ}$}

\section{Movimientos y Planos Cinematográficos}

Los movimientos y los planos cinematográficos empleados en Lancelot revelan la adhesión del autor a los principios estéticos de la vanguardia. Blasco Ibánez, a pesar de practicar sobre todo una literatura realista y naturalista, había defendido que en el cine se encontraba la renovación de la literatura española: «Si los novelistas empiezan a intervenir directamente en el desarrollo del "séptimo arte" [...] su esfuerzo servirá cuando menos para reanimar la novela» (Blasco Ibáñez 1922: 11). Esta afirmación coincide con la opinión del vanguardista Guillermo de Torre, que vio en este medio la posibilidad de "crear un nuevo ritmo y una nueva lengua expresiva, llena de frescura y de emoción» (2003 [1925]: 328). También en un artículo pionero, que De Torre publicó en la revista Cosmópolis (Madrid, 19191922) en 1921, el escritor señaló la intensa relación entre cine y poesía nueva en esa década (Torre 1921: 100). Para reflejar esta combinación de lenguajes artísticos, De Torre (2003 [1925]: 328) usó en su obra Literaturas europeas de vanguardia (1925) el término cinegrafía, que se ajusta a cómo Espinosa recurre al cine en determinados pasajes de Lancelot. También Antonio Espina empleó este término en un artículo titulado "La cinegrafía en la novela moderna», donde explicó que el cine aportaba a la literatura nuevas velocidades narrativas y diversos juegos visuales (1928 [8 de julio]: 1). La literatura, combinada con este medio audiovisual, da lugar en Lancelot a un texto que ofrece visiones inéditas de la isla.

Siguiendo la clasificación de Lough (2005: 410) de los diferentes rasgos fílmicos presentes en las obras literarias, en Lancelot se advierten los tres tipos de influencia que el cine ejerce en la literatura: la intertextual, que consiste en aludir 
a obras, intérpretes, géneros cinematográficos u otros aspectos de esta industria; la metafórica, en la que se crean imágenes poéticas a través de vocabulario cinematográfico o de diversas cualidades vinculadas al cine; y la técnica, que se manifiesta en el traslado de procedimientos fílmicos a la literatura. El estudio de la influencia intertextual del cine en la literatura resulta relativamente sencillo de llevar a cabo, pues, aunque en algunos textos se hallan referencias difíciles de esclarecer, casi siempre existen indicios que sugieren -con más o menos ambigüedad-a qué aspecto del mundo fílmico se alude. Del mismo modo, se aprecia una influencia metafórica del cine sobre la literatura cuando en el tex to se observa el uso de cualidades -como la rápida sucesión de imágenes- o de vocabulario asociados a este medio audiovisual.

Sin embargo, el análisis de la influencia técnica del cine en la literatura plantea numerosos problemas. A veces resulta muy complicado saber si una perspectiva visual concreta, una imagen descrita o determinados procedimientos narrativos poseen un origen fílmico o no. Las dificultades que plantean estos análisis aumentan cuando no existen declaraciones explícitas de los autores sobre esta influencia en prólogos, en epílogos, en entrevistas, en cartas o en otros documentos. El mismo problema persiste cuando no se hallan evidencias textuales que apoyen esa interpretación, como el subtítulo de «novela cinematográfica» o el uso de vocabulario fílmico. Esta dificultad ha derivado, en ocasiones, en la exageración de la influencia real del cine en la literatura, sobre todo tras el surgimiento de las teorías precinematográficas, que defienden la existencia de técnicas fílmicas en obras escritas antes de la invención del cinematógrafo. Leglise (1958), que ha apreciado recursos cinematográficos en la Eneida de Virgilio, se encuentra entre los primeros defensores relevantes de esta postura crítica. Peña-Ardid explica cómo estas teorías influyeron en los estudios comparatistas de la literatura y el cine:

La "cinemanía» aplicada, como denomina Jorge Urrutia a la moda de los estudios precinematográficos, tuvo el efecto positivo de implicar un poco más a la crítica literaria en algunos temas relacionados con el cine, pero lo hizo en una dirección bastante equivocada y propiciando el uso indiscriminado de la terminología técnica del cine para caracterizar las obras de la literatura del pasado y del presente. En cualquier descripción podían encontrarse primeros planos, panorámicas, travellings; todo tipo de fracturas de la acción narrativa implicaba montaje cinematográfico o la más mínima demora parecía la técnica del ralentí (2009 [1996]: 79).

En Lancelot, en cambio, el análisis de técnicas cinematográficas se justifica por dos motivos. Primero, la obra se escribió en un contexto de vanguardia en el que se consideraba que las constantes relaciones entre la literatura y el cine ofrecían nuevas posibilidades creativas a los autores que incorporaran procedimientos fílmicos en sus escritos. Segundo, Espinosa demostró en diferentes textos y a lo largo de su vida el enorme interés que siempre sintió por el medio audiovisual. Por ello, resulta coherente que Espinosa imitara distintas técnicas cinematográficas en Lancelot. La primera de ellas se encuentra en el capítulo de «Nazaret», donde se describe este pueblo desde lejos. El movimiento del coche en el que se halla el narrador, que se acerca poco a poco a Nazaret, convierte su mirada en una suerte de cámara que 
observa el paisaje en un travelling avant ${ }^{5}$. Así, como recuerda Ródenas de Moya (2009: 119), los planos fílmicos «cobran una insospechada relevancia cuando se conjugan con el movimiento, del ojo y de los objetos que componen el cuadro, para formar fragmentos narrativos». De este modo, lo que en principio se percibe como unas líneas blancas cobra volumen hasta conformar las casas del pueblo de Nazaret:

Alguien ha trazado sobre la lejanía última de la ancha estepa -subrayando el cielo diáfano del mediodía- 2, 3 rayas blancas, 2, 3 líneas blancas, rectas, largas, como rayas de campo de deportes: 2, 3 rayas blancas sobre un extremo del amplio pizarrón sin marco que el automóvil dilata en cada nuevo kilómetro. Así la Nazaret del primer horizonte.

Luego las 2, 3 rayas blancas se han segmentado, han engrosado, se han ido levantando desperezosamente. Para estar ya de pie, alegres -lavadas y empolvadascuando tocamos la meta de Nazaret (Espinosa 1929: 33).

En otros pasajes, la influencia técnica del cine se aprecia en el punto de vista espacial que se adopta para describir una imagen. Una de las metáforas que se observan en Lancelot se basa, precisamente, en el plano contrapicado. En el capítulo dedicado al «lago» de Janubio, el narrador contempla cómo las salinas hablan con el viento para invitarle a jugar con ellas. Le piden que levante sus espumas blancas y que las eleve a donde quiera: «Se trata, sólo, de que aprendas a cazar mis espumas. Aprésalas como pueda [sic]. Llévalas donde quieras. Hacia el Norte, hacia el Sur, hacia el Este, hacia el Oeste» (Espinosa 1929: 97). Las salinas quieren, además, que «los hombres de la Isla las vean» (Espinosa 1929: 97). Y la perspectiva desde la que los habitantes de Lanzarote las observan corresponde a un plano contrapicado, pues las ven desde abajo -la costa- hacia arriba -el cielo-. De esta manera, confunden las espumas voladoras con aves: «Creerán que son pájaros blancos. Tú les dirás que son pájaros blancos, hijos del pato más albo y de la ola más salada del lago» (Espinosa 1929: 97). En estas líneas el plano contrapicado ha convertido un espectáculo natural en una imagen poética que resalta la belleza de las salinas y de la costa de Lanzarote.

Espinosa incluye numerosas ilustraciones, realizadas por él, que muestran algunos de los lugares descritos. Una de ellas corresponde al puerto de Naos, visto en el dibujo desde un plano cenital. Así presenta con claridad la estricta organización con la que atracan los barcos, que forman una figura casi simétrica: «El tonelaje ordena las embarcaciones del puerto. Los clasifica y uniforma. Construye las filas» (Espinosa 1929: 89). Se trata, por tanto, de una imagen imposible de ver para cualquier humano que no recurra a la tecnología adecuada. La mirada cinematográfica ofrece una visión inédita del puerto, que se distingue de los antiguos por el orden que rige en él: a diferencia de los puertos románticos del siglo xix, en el de Naos los barcos ya no parecen «aventureros del océano", sino "papeletas en un fichero» (Espi-

5 García Gómez define este travelling como un «movimiento hacia el referente que tiene una dirección opuesta a la cámara, a la que se dirige» (2015: 213). 
nosa 1929: 91). Este cambio tan notable en el modo de atracar exige una interpretación distinta del puerto de Naos, que se consigue gracias al plano cenital.

En el capítulo "Tinajo o el bizantinismo» el cine se manifiesta en una escritura próxima al estilo de un guion cinematográfico, tal como señala Pérez Corrales (1983: 470). El cura del pueblo, Tomás Romero, llega en caballo y se detiene junto al narrador: «(Ha frenado su prodigioso caballo. Vacilan los cascos un momento. Se afirman luego enérgicamente)» (Espinosa 1929: 63). Al describir con precisión cómo frenan los cascos, se sugiere un plano detalle de las patas del animal para transmitir al lector la sensación de que las ve de cerca. Unas líneas después, el narrador centra por un instante su atención en el sombrero del cura: «Tomás Romero está ahora junto a su caballo. En una mano el sombrero» (Espinosa 1929: 65). Esta referencia a la manera en que lo sujeta evoca también un plano detalle de la prenda. De este modo, se anuncia con sutileza la importancia que los sombreros adquirirán en el capítulo. El cura usará varios de ellos para revelarle al narrador el «secreto de Tinajo» (Espinosa 1929: 67), que radica en la influencia oriental de la arquitectura del pueblo. Tomás Romero deja en la plaza "veinte sombreritos» (Espinosa 1929: 67) que imitan la forma de las cúpulas bizantinas que, a su juicio, se distinguen en las casas de Tinajo.

\section{IMÁGENES POÉTICAS VINCULADAS CON EL CINE}

Como señala García Montero, un tipo de influencia que el cine ejerce en la literatura -y que en este artículo se denomina metafórica-consiste en el uso de imágenes poéticas vinculadas al dinamismo que los vanguardistas asociaban con las películas, sobre todo las cómicas: «[...] las imágenes poéticas que se asocian regularmente con el cine tienen siempre que ver con la velocidad o con el cauce abstracto, sin materia, de su fluido» (García Montero 2000: 391). El propio Espinosa identificaba el cine con la rapidez: «Los aspectos se suceden rápidos, como se suceden las escenas de una cinta cinematográfica»(Espinosa 1931: 14). Por este motivo, en Lancelot el viento posee un protagonismo especial no solo por formar parte de la meteorología de Lanzarote, sino por la intensidad con la que sopla sobre la isla. La primera alusión relevante al viento se encuentra en el capítulo "Mozaga», donde, personificado, se encarga de mantener separadas las casas de este pueblo y las de Nazaret: «[...] a las pocas horas, el viento NE. llevaba de nuevo a Mozaga a su situación primigenia» (Espinosa 1929: 41). Sin embargo, el viento cobra verdadero protagonismo en el capítulo «Biología del viento de Lanzarote», donde interacciona con el paisaje: «Aprendió allí a jugar maravillosamente con las arenas» (Espinosa 1929: 46).

La relación del viento con el cine radica en su dinamismo, exaltado a su vez en metáforas deportivas que lo convierten en un atleta veloz. El deporte se convirtió en un nuevo espectáculo del siglo xx y, como indica Pérez Corrales, «algo similar ocurría al mismo tiempo con el cine» (1986: 124). Ambas disciplinas se incorporaron al imaginario de las vanguardias, de modo que el entusiasmo por la velocidad que promueve el cine se extiende también al mundo de los deportes. Maruja Mallo reflejó bien este dinamismo deportivo en su cuadro Elementos para el deporte (1927), en el que una enorme raqueta de tenis se entrecruza con una avioneta (Nuevo Cal 
2017: 20). De este modo, la agilidad física que exige el deporte se combina con los modernos aparatos aeronáuticos, que se convierten en símbolos de la velocidad que exaltaban las vanguardias.

Espinosa crea en Lancelot metáforas similares a la del cuadro de Mallo que entremezclan el mundo de la aviación y el del deporte, representados ambos por el viento. Cuando este nace en África realiza un "gran salto heroico sobre el Océano» (Espinosa 1929: 50) para llegar a Lanzarote, cruza una "pista veraniega para el gran salto atlético África-Canarias» (Espinosa 1929: 50), efectúa un «raid interparálico» (Espinosa 1929: 50) y supera una "prueba de Gyncana [sic] imprevista» (Espinosa 1929: 50-51). Como se aprecia, el viento conecta el continente africano con el archipiélago canario gracias a sus aptitudes deportivas, con las que sortea el mar. De la misma manera, otras metáforas convierten el viento en un avión que destaca por su velocidad. Esta vinculación entre paisaje y nuevos medios de transporte también la recoge García Montero, quien indica que, en las vanguardias, a través de «las ventanillas de un automóvil, un tren o un avión» (2000: 391$)$ se presentan las imágenes con un dinamismo cinematográfico. Por eso el viento vuela como un "avión arénico» (Espinosa 1929: 51), realiza «aterrizajes violentos» (Espinosa 1929: 51) y se considera a sí mismo un "aeronauta absoluto de los mares» (Espinosa 1929: 51).

En el capítulo "Elogio de la palmera con viento» la velocidad fílmica dinamiza un elemento estático. La palmera se ha instalado en la isla para cumplir su sueño: hacer girar sus ramas. Ha sentido envidia de artefactos creados para girar sobre sí mismos, como las ruletas, los discos de gramófono y los tiovivos. Pero la palmera, gracias al viento, consigue imitar a los molinos: «Eres ya la primera entre todas las cosas que han aprendido el arte de la voltereta alrededor de un punto absoluto» (Espinosa 1929: 56). Este movimiento circular también remite a unos objetos que simbolizaban la modernidad de los años veinte: las hélices de los aviones. Por este motivo, el narrador se dirige así a la palmera: «Eres -hoy- la única hélice» (Espinosa 1929: 56).

En el capítulo «Teguise y Clavijo Fajardo» se recurre de nuevo a este mismo movimiento. El narrador dinamiza el pueblo de Teguise para resaltar su paisaje pintoresco. Ante su mirada cinematográfica, el lugar se convierte en una suerte de ruleta multicolor: «Teguise es un pueblecito alegre, rumoroso, que hace girar su rueda de colores frente a la blanca arquitectura general de la isla» (Espinosa 1929: 72). Para acentuar más este contraste entre Teguise y el resto de la isla, el pueblo no solo gira sobre sí mismo. También presenta un "correr regocijado de película de Harold [Lloyd]» (Espinosa 1929: 72) que exalta la intensidad con la que el narrador percibe el paisaje.

Asimismo, la influencia metafórica del cine se manifiesta en el capítulo "Mapa buico», donde el uso de vocabulario fílmico crea una imagen poética a partir del paisaje. El personaje del caballero Lancelot habita un espacio que se presenta como un decorado cinematográfico: «La escenografía caballeresca -castillo claro, oscuro laberinto- rodela doble y doble redil» (Espinosa 1929: 115). El mito que el autor inventa para una isla nueva, con un pasado distinto, exige un paraje medieval en el que viva el caballero bretón. El castillo que el autor imagina como morada de Lancelot se convierte, en esta cita, en un decorado escenográfico listo para el rodaje. 
La mayoría de las referencias intertextuales fílmicas en Lancelot, $28^{\circ}-7^{\circ}$ se concentra en "Elogio del camello con arado», donde resalta la importancia de este animal en la zona rural de Lanzarote. Todas las menciones de este capítulo corresponden a estrellas del cine mudo cómico estadounidense. El narrador no ve el camello al que se dirige como un animal de tiro ni como una atracción turística, sino como un "gran actor de la estepa" (Espinosa 1929: 30). Sin proponérselo, el camello deleita al público con su "gran "film" para minorías" (Espinosa 1929: 30). Su melancólica expresión corporal incluso recuerda al famoso vagabundo que creó Charlie Chaplin: «Con una gracia tan triste que únicamente Charlot podría llamarte su maestro" (Espinosa 1929: 29). El narrador se siente igual que ante una proyección y se considera a sí mismo un "espectador regocijado de tu gran arte inédito" (Espinosa 1929: 30).

El talento insospechado del camello lo pone al mismo nivel de otros grandes cómicos del cine mudo: «Si tú fueras a Nueva York -camello, con arado, de Lanzarote- encontrarías el empresario para tus películas. Trabajarías con Pamplinas y con Mary Pickford, con Charles Chaplin y con Harold» (Espinosa 1929: 30). La mención de estas estrellas resulta significativa, pues demuestra que Espinosa conocía bien el cine cómico estadounidense de los ańos veinte. Todos los actores nombrados provienen de ese país: Pamplinas es el apodo que en España se dio a Buster Keaton (Pérez Corrales 1986: 404) y con Harold se alude a Harold Lloyd. Asimismo, todos pertenecen al cine mudo porque probablemente, hasta la publicación de Lancelot, era el único que Espinosa había conocido. El cine sonoro comenzó en 1926 con Don Juan, de Alan Crosland, aunque esta película solo contenía efectos sonoros y música. En The Jazz Singer (1927), que también dirigió Crosland para la productora Warner Bros, sí se incluyeron números musicales y algunos diálogos. Sin embargo, la primera proyección sonora no se realizó en España, en concreto en Barcelona, hasta septiembre de 1929, cuando el cine Coliseum estrenó La canción de París (Innoccents of Paris, 1929), de Richard Wallace (Gómez Bermúdez de Castro 1993: 99). En cambio, en Canarias el cine sonoro llegó en otoño de 1930 con la película alemana Troika (1930), de Vladimir Strizhevsky (Pérez Corrales 2018: 201).

No obstante, cuando a comienzos de los años treinta el cine sonoro ya ha ocupado gran parte de las carteleras, Espinosa lo rechaza en favor del mudo. Para él, la incorporación del sonido a las películas contravenía la verdadera naturaleza de este medio. Así lo expresó en su artículo "Mosén Cinema, madame Lira y don Odeón", publicado en La Gaceta Literaria en 1931: «El cinema, sin embargo, desaparece borrado por el cinema sonoro, que no es estricto cinema» (Espinosa 1931: 14). Dos años después, el autor incluso calificó a las películas sonoras como una "vergüenza» (Espinosa 2018 [1933]b: 200). Desde su perspectiva, la incorporación de la palabra hablada a las películas les daba un carácter teatral y las alejaba del auténtico cometido del cine: ofrecer imágenes en movimiento. Espinosa se suma a escritores que también condenaban este cambio con artículos como «Notas de un espectador enojado», de 1933, que supone, como explica Pérez Corrales, su «más virulento y sistemático repudio del cine americano sonoro y sentimentaloide» (1986a: 121). En 
este texto, al hablar de Remordimiento (1932), critica esta película porque la considera «una huida del cine y una vuelta al viejo teatro espectacular» (Espinosa 2018 [1933]a: 212). Por ello, Morris (1980: 31) incluye a Espinosa entre los escritores que se opusieron a las películas habladas.

Junto con la intertextualidad explícita al mundo del cine, también existen en Lancelot referencias intertextuales implícitas. En "Teguise y Clavijo Fajardo" se describe a las mujeres del pueblo así: «... las mujercitas de andar jaguarino y largo mirar de novias de "film” yanqui» (Espinosa 1929: 72). Los adjetivos «jaguarino" $\mathrm{y}$ "yanqui» sugieren que tras esta mención cinematográfica se encuentra la actriz estadounidense Theda Bara. Como señala Conget (2002: 404), ella popularizó en el cine las femmes fatales a las que, en apariencia, alude el andar jaguarino de las mujeres de Teguise. Bara interpretó a Cleopatra, a Salomé y a otras mujeres seductoras, no exentas en ocasiones de cierta maldad, que se ajustaban al modelo de mujer fatal (Sánchez del Molino 2015: 92). Asimismo, existe la posibilidad de que Espinosa equiparara el «largo mirar de novia» con la mirada de Bara, que Sánchez del Molino describe como unos ojos rodeados de sombras oscuras que «le otorgan un aspecto misterioso de seductora y peligrosa mujer fatal» (2015: 93).

En la descripción del puerto de Naos existe otra referencia cinematográfica, en este caso a la productora alemana UFA: «Entre los pailebotes distingo el Mercurio, modelo para "film" marino de la Ufa" (Espinosa 1929: 91). Esta mención revela la importancia que los miembros de La Gaceta Literaria le daban a esta compañía, que en los ańos veinte sobresalía por haber producido grandes películas del cine expresionista alemán, como El gabinete del doctor Caligari (Das Kabinett des Dr. Caligari, 1920), de Robert Wiene. Este filme se proyectó en el cineclub de la revista en 1929 (Sánchez Millán 1991: 359), año en el que también se anunció en La Gaceta Literaria una sesión de homenaje a la UFA organizada en el cineclub («Noticias del cineclub», 1929 [15 de febrero]: 6). Por tanto, la referencia a esta productora que incluye Espinosa en Lancelot, a pesar de que no se acompaña de ninguna reflexión sobre su relevancia, demuestra el interés del autor por las películas de esta compañía.

La última alusión cinematográfica se halla en el «Final», donde se describen con sobriedad pinturas religiosas repartidas por distintos puntos de la isla. Uno de los cuadros, titulado Ánimas, representa la lucha entre san Miguel y Satanás, en la que el arcángel expulsa al demonio del cielo. Sin embargo, el narrador no se acerca a estas pinturas como un devoto, sino como alguien imbuido en las vanguardias. Por este motivo, no ve una lucha cristiana entre el bien y el mal, pero sí un baile de los ańos veinte: «San Miguel baila el charleston [sic] sobre la barriga del Diablo. Lección para Josefina Baker» (Espinosa 1929: 126). Aunque la bailarina estadounidense Josephine Baker, tras llegar a París en 1925, «impulsó en el continente la moda del charlestón» (Gubern 2005: 291), ganó popularidad sobre todo gracias a las películas en las que actuó a finales de la década de 1920. Según Ródenas de Moya (2005: 293), su primera incursión en el cine se produjo en el filme La sirène de tropiques (1927), de Mario Nalpas y Henri Étiévant. Sin embargo, Gubern (2005: 291) explica que su verdadera fama en España no le llegó hasta comienzos de 1930, cuando visitó el país en una gira mundial. No obstante, antes de esa fecha Baker ya formaba parte del imaginario colectivo de los vanguardistas españoles gracias a sus colaboraciones 
cinematográficas. Así lo prueba su mención no solo en Lancelot, sino también en el ensayo Indagación del cinema (1929), de Francisco Ayala. En esta obra el autor dedica un capítulo a Baker en el que define a esta bailarina afroamericana como «una egregia representación de su raza en el mundo del cine» (Ayala 1929: 150).

\section{CONCLUSIONES}

El análisis de los recursos cinematográficos empleados por Espinosa en Lancelot proporciona una información valiosa para comprender mejor cómo el autor concebía el cine. Espinosa se revela en Lancelot como un verdadero entusiasta del cine mudo, sobre todo el estadounidense. Las alusiones explícitas e implícitas a estrellas de aquel momento y a la productora alemana UFA prueban sus notables conocimientos sobre el cine de entonces, que forma parte fundamental de su imaginario y del de sus coetáneos. Su inclusión en Lancelot obedece, por tanto, al deseo de Espinosa de alejar Lanzarote de representaciones costumbristas y convertir su insularidad en una inquietud vanguardista. De este modo, Espinosa demuestra que, como defiende Padorno, «lo canario no es enemigo del espíritu de la vanguardia y, lejos de incitar a la ruptura de la tradición interna, invita a fortalecerla» (2000: 20).

Además, aunque Espinosa no emplea términos técnicos del mundo del cine, a lo largo del texto se hallan movimientos y planos fílmicos con los que el autor buscaba imágenes inéditas de la isla y la dinamización de sus paisajes. Así, Lancelot contribuye al debate que diversos escritores mantenían en la década de 1920 sobre cómo el cine renovaba la literatura y aportaba ritmos y puntos de vista inexplorados hasta entonces. Con esta obra Espinosa ha profundizado en la búsqueda de una expresión interartística que combine el lenguaje literario y el cinematográfico. De esta manera, el escritor despoja a los lectores de la mirada regionalista desde la que se ha descrito Lanzarote en textos literarios y en guías turísticas para convertirlos en espectadores de su peculiar concepción de la isla.

Por todo ello, Espinosa ha logrado su objetivo de «crear un Lanzarote nuevo» (Espinosa 1929: 12). Como explican Pérez Hernández y Becerra Bolaños, el autor ha establecido un innovador diálogo «con la tradición en el sentido más amplio» (2011: 84), abarcando tanto el paisaje, la historia, la literatura y el arte. De esta particular visión de la insularidad surge una corografía vanguardista que, al mismo tiempo, funciona como "una bellísima guía poética de la isla» (P. Corrales 1999: 71) en la que el cine condiciona la manera de observar Lanzarote. Los recursos técnicos e intertextuales que conformaban el bagaje cinematográfico de Espinosa le permitieron ofrecer un Lanzarote literario alejado de corrientes regionalistas. El autor contempla la isla a través de una mirada vanguardista que se ha formado, en gran medida, ante la gran pantalla. Por este motivo, al usar el cine para describir Lanzarote, Espinosa actualiza el paisaje e inventa un espacio insular en el que los habitantes del siglo xx ven al fin reflejadas sus inquietudes artísticas e intelectuales. 


\section{BIBLIOGRAFÍA}

«Desde Icod. De cine» (1931 [10 de mayo]): La Prensa, Santa Cruz de Tenerife, 4582, 2.

«Noticias del cineclub» (1929 [15 de febrero]): La Gaceta Literaria 52, 6.

Alberti, Rafael (1981 [1929]): Sobre los ángeles. Yo era un tonto y lo que he visto me ha hecho dos tontos, edición de C. Brian Morris, Madrid: Cátedra.

Armas Ayala, Alfonso (1960): Espinosa, cazador de mitos, Puerto de la Cruz, Tenerife: Instituto de Estudios Hispánicos.

Armas Ayala, Alfonso (1992): «El Lancelot de A. Espinosa», en Carlos Gaviño de Franchy (ed.), Encuentro de escritores canarios, Canarias: Viceconsejería de Cultura y Deportes del Gobierno de Canarias, 267-274.

Armas, Alfonso (1968): «Prólogo», en Agustín Espinosa, Lancelot, $28^{\circ}-7^{\circ}$. (Guía integral de una isla atlántica), edición de Alfonso Armas, Las Palmas de Gran Canaria: Litografía Saavedra, VII-XV.

Armas, Alfonso (1974): «Prólogo», en Agustín Espinosa, Crimen; Lancelot, $28^{\circ}-7^{\circ}$ (guía integral de una isla atlántica); Media hora jugando a los dados, edición de Alfonso Armas, Madrid: Taller de Ediciones Josefina Betancor, 9-32.

Ayala, Francisco (1929): Indagación del cinema, Madrid: Compañía Ibero-americana de Publicaciones.

Baroja, Pío (1929): El poeta y la princesa o El cabaret de la Cotorra Verde, Madrid: Atlántida.

Benítez Toledo, José M. (1928): Charlestón, Santa Cruz de Tenerife: Imprenta de Juan Sans Cartanyá.

Betancort Mesa, José Ramón (2019): «Un Lanzarote inventado por mí. A propósito de Lancelot, $28^{\circ}-7^{\circ}$ de Agustín Espinosa», en Agustín Espinosa, Lancelot, $28^{\circ}-7^{\circ}$. Guía integral de una isla atlántica, edición de Roberto García de Mesa y José Ramón Betancort Mesa, Madrid: Itineraria Editorial, 21-33.

Blasco Ibáñez, Vicente (1922): El paraiso de las mujeres, Valencia: Prometeo.

Castells, Isabel (2009): «La isla vanguardista: crisol e infierno», en Domingo-Luis Hernández (ed.), Isla Vanguardia, Santa Cruz de Tenerife: La Página Ediciones, 25-48.

Castilla, Carlos (1985): «El cine a través de La Gaceta Literaria y del Cineclub de Ernesto Giménez Caballero", Poesía. Revista ilustrada de información poética 22, 19-62.

Conget, José María (2002): Viento de cine. El cine en la poesía española de expresión castellana (19001999), Madrid: Hiperión.

Dandin (1926 [29 de agosto]): «Artistas y escritores de La Orotava», Hespérides 35, 14.

De la Nuez Caballero, Sebastián (1983): «Agustín Espinosa, la persona y su estilo», Revista de Filología de la Universidad de La Laguna 2, 3-20.

Díaz Arenas, Ángel (2015): Agustín Espinosa: primer surrealista español. Vida, destino y obra, Vigo: Academia del Hispanismo.

Díez del Corral, Eduardo (1927 [11 de diciembre]): «La herencia de Augusto Darley», Hespérides 99, 14.

Espina, Antonio (1928 [8 de julio]): «La cinegrafía en la novela moderna», El Sol, 1.

Espinosa, Agustín (1929): Lancelot, $28^{\circ}-7^{\circ}$, Madrid: Alfa. 
Espinosa, Agustín (1931): «Mosén Cinema, madame Lira y don Odeón», La Gaceta Literaria 111, 14.

Espinosa, Agustín (2014): Obra completa, compilación de Domingo-Luis Hernández, El Sauzal, Tenerife: La Página.

Espinosa, Agustín (2017 [1930]): «Elogio de la burbuja», en Agustín Espinosa, Oda a María Ana, primer premio de exilas sin depilar de 1930. Textos 1930-1931, edición de José Miguel Pérez Corrales, Tenerife: Insoladas, 111-113.

Espinosa, Agustín (2018 [1933]a): «Notas de un espectador enojado», en Agustín Espinosa, Media hora jugando a los dados. Textos 1932-1933, edición de José Miguel Pérez Corrales. Tenerife: Insoladas, 211-214.

Espinosa, Agustín (2018 [1933]b): «Un coleccionista en el cine», en Agustín Espinosa, Media hora jugando a los dados. Textos 1932-1933, edición de José Miguel Pérez Corrales. Tenerife: Insoladas, 199-200.

Espinosa, Agustín (2018): La quimera del sueño. Obra completa, compilación de Domingo-Luis Hernández, El Sauzal, Tenerife: La Página.

Fuentes, Alfredo (1929): Flor de los campos, La Orotava: Imprenta Antonio Herreros.

García de Mesa, Roberto. (2008): «Las vanguardias literarias y el cine en Canarias: "Escándalo”, poema inédito de Domingo López Torres", Estudios Canarios. Anuario del Instituto de Estudios Canarios 50-51, 631-641.

García Gómez, Francisco José (2015): Metodología crítica de análisis textual en la realización fílmica, Madrid: Universidad Complutense. URL: https:/goo.gl/G0tTuZ; 4/9/2020.

García Lorca, Federico (2002 [1928]): «La muerte de la madre de Charlot», en José María Conget (ed.), Viento de cine. El cine en la poesía española de expresión castellana (1900-1999), Madrid: Hiperión, 66-70.

García Lorca, Federico (2008 [1928]): El paseo de Buster Keaton, Valencia: Media Vaca.

García Montero, Luis (2000): «El cine y la mirada moderna», en Gabrielle Morelli (ed.), Ludus. Cine, arte y deporte en la literatura española de vanguardia, Valencia: Pretextos, 387-401.

Gómez Bermúdez de Castro, Ramiro (1993): «La transformación del cine mudo al sonoro en España (1929-1931). Los costes económicos», en El paso del mudo al sonoro en el cine español, Actas del IV Congreso de la AEHC, Madrid: Editorial Complutense, 97-108.

Gómez de la Serna, Ramón (1923): Cinelandia, Valencia: Editorial Sempere.

Gómez Gutiérrez, Beatriz (2008): Les mythes et leurs métamorphoses dans l'œuvre d'Agustín Espinosa (1897-1939), París: Université Paris-Sorbonne-Paris IV. URL: https://goo.gl/MJnsmW; $4 / 9 / 2020$.

González González, Francisco (1928): La hija del «Mestre», Las Palmas de Gran Canaria: Gran Canaria Films. URL: https://bit.ly/3elWcEy; 4/9/2020.

González Maya, Juan C. (2017): «Encomiástica cristiana en la Historia de Jaén, de Jiménez Patón y Ordóńez de Ceballos», Anuario de Historia de la Iglesia 26, 409-436.

Gubern, Román (1999): Proyector de luna. La Generación del 27 y el cine, Barcelona: Anagrama.

Gubern, Román (2005): «Ruido, furia y negritud: nuevos ritmos y nuevos sones para la vanguardia», en Mechthild Albert (ed.), Vanguardia española e intermedialidad. Artes escénicas, cine y radio, Frankfurt: Iberoamericana/Vervuert, 273-302. 
Gutiérrez Albelo, Emeterio (1933): Romanticismo y cuenta nueva, Tenerife: Ediciones de Gaceta de Arte.

Guzmán Arias, Carmen (1989): «Introducción», en Pomponio Mela, Corografía, Murcia: Universidad de Murcia, 11-28.

Heredia, María Isabel (1992): «La obra de Agustín Espinosa», en Andrés Sánchez Robayna (ed.), Canarias: las vanguardias históricas, Las Palmas de Gran Canaria: Centro Atlántico de Arte Moderno / Viceconsejería de Cultura y Deportes del Gobierno de Canarias, 99-114.

Leglise, Paul (1958): Une cuvre de pré-cinéma: l'Eneide. Essai d'analyse filmique du premier chant, París: Nouvelles Éditions Debresse.

Llarena, Alicia (2000): "Algunas divagaciones espinosas: Lancelot $28^{\circ}-7^{\circ}$ », en Antonio Becerra Bolaño y Domingo Fernández Agis (eds.), La cultura vanguardista en Canarias. Reflexiones sobre la obra de Agustin Espinosa, Granada: Proyecto Sur Ediciones, 53-71.

Lough, Francis (2005): «Jarnés y el cine», en Mechthild Albert (ed.), Vanguardia española e intermedialidad. Artes escénicas, cine y radio, Frankfurt: Iberoamericana/Vervuert, 407-422.

Martín Rodríguez, Fernando Gabriel (1992): «El cine y la vanguardia en Canarias», en Andrés Sánchez Robayna (ed.), Canarias: las vanguardias históricas, Las Palmas de Gran Canaria: Centro Atlántico de Arte Moderno, 141-177.

Morris, C.B. (1980): This Loving Darkness. The Cinema and Spanish Writers 1920-1936, New York: Oxford University Press.

Müller, Carlos (2006): «Lanzarote y Agustín Espinosa. Prólogo del traductor», en Agustín Espinosa, Lancelot, $28^{\circ}-7^{\circ}$, Umfassender Führer einer Atlantischen Insel, Lanzarote: Patronato de Turismo del Cabildo de Lanzarote, 6-17.

Nuevo Cal, Carlos (2017): «Maruja Mallo, artista universal (1921-1936)», Cuadernos de Estudos Xerais 9, 3-21.

PAdorno, Eugenio (2000): «Una reflexión sobre el signo cultural canario: Viera y Espinosa», en Antonio Becerra Bolaño y Domingo Fernández Agis (eds.), La cultura vanguardista en Canarias. Reflexiones sobre la obra de Agustin Espinosa, Granada: Proyecto Sur Ediciones, 13-25.

Palenzuela, Nilo (2002 [1988]): «Prólogo», en Agustín Espinosa, Lancelot, $28^{\circ}-7^{\circ}$, edición de Nilo Palenzuela, Lanzarote: Interinsular Canaria, 9-33.

Peña-Ardid, Carmen (2009 [1996]): Literatura y cine, Madrid: Cátedra.

Pérez Corrales, Miguel (1999): Entre islas anda el juego. (Nueva literatura y surrealismo en Canarias, 1927-1936), Teruel: Museo de Teruel.

Pérez Corrales, José Miguel (2018): «Nota del editor», en Agustín Espinosa, Media hora jugando a los dados. Textos 1932-1933, edición de José Miguel Pérez Corrales, Tenerife: Insoladas, 201-202.

Pérez Corrales, José Miguel (2019 [2013]): «Agustín Espinosa: Lancelot, $28^{\circ}-7^{\circ}$ y otros escritos de los años 20», en Agustín Espinosa, Lancelot, 28-7. Textos 1927-1929, edición de José Miguel Pérez Corrales, Tenerife: Insoladas, 305-352.

Pérez Corrales, Miguel (1983): «La isla inventada de Agustín Espinosa», Anuario de Estudios Atlánticos 29, 453-527.

Pérez Corrales, Miguel (1986a): Agustín Espinosa, entre el Mito y el Sueño, tomo i, Las Palmas de Gran Canaria: Ediciones del Cabildo Insular de Gran Canaria. 
Pérez Corrales, Miguel. (1986b): Agustín Espinosa, entre el Mito y el Sueño, tomo II, Las Palmas de Gran Canaria: Ediciones del Cabildo Insular de Gran Canaria.

Pérez Hernández, Nayra, y Antonio Becerra Bolaños (2011): «Creación vanguardista de espacios dislocados: Canarias y Guinea, de Agustín Espinosa a Agustín Miranda», Iberoromania. Revista dedicada a las lenguas, literaturas y culturas de la Peninsula Ibérica y de América Latina 73-74, 76-89.

Ródenas de Moya, Domingo (2005): «Proyección estética y literaria del baile en los años 20», en Mechthild Albert (ed.), Vanguardia española e intermedialidad. Artes escénicas, cine y radio, Frankfurt: Iberoamericana/Vervuert, 303-316.

Ródenas de Moya, Domingo (2009): Travesías vanguardistas. Ensayos sobre la prosa del Arte Nuevo, Madrid: Devenir.

SÁnChez del Molino, Iria (2015): La figura de la femme fatale en el cine negro americano: «Double Indemnity» (Billy Wilder, 1944), Las Palmas de Gran Canaria: Universidad de Las Palmas de Gran Canaria. URL: https://goo.gl/m5nGk5; 4/9/2020.

SÁnchez Millán, Alberto (1991): «La vanguardia cinematográfica en el cine-club español y La Gaceta Literaria (nota informativa)", en Actas del III Congreso de la AEHC, San Sebastián: Filmoteca Vasca, 353-361. URL: https://goo.gl/c8oyiE; 4/9/2020.

Torre, Guillermo de (1921): «El cinema y la novísima literatura: sus conexiones», Cosmópolis 33, 97-107.

Torre, Guillermo de (2003 [1925]): Literaturas europeas de vanguardia, edición de José Luis Calvo Carilla, Pamplona: Urgoiti Editores.

Trujillo, Juan Manuel (2019 [1929]): «La nueva literatura. Un libro de Agustín Espinosa», en Agustín Espinosa, Lancelot, $28^{\circ}-7^{\circ}$. Textos 1927-1929, edición de José Miguel Pérez Corrales, Tenerife: Insoladas, 299-304.

Vilá Valentí, Juan (1989): El conocimiento geográfico de España. Geógrafos y obras geográficas, Madrid: Síntesis. 